International Journal of Child, Youth and Family Studies (2013) 3: 371-380

\title{
MOVING TOWARDS EMANCIPATORY PRACTICE: CONDITIONS FOR MEANINGFUL YOUTH EMPOWERMENT IN CHILD WELFARE
}

\section{Jennifer Dupuis and Varda Mann-Feder}

\begin{abstract}
What are conditions that facilitate the development of youth voice in child welfare? This article will build on current literature that emphasizes the critical importance of treating youth in the care of the public system as valued resources and agents of change in their own lives who can contribute to effective service delivery. A focus will be on comparing principles of youth empowerment and the general purpose of child welfare systems in Canada and the United States. Challenges to the implementation of this model will be highlighted and recommendations to facilitate its execution at the individual, organizational, and policy development levels of our youth serving agencies will be made.
\end{abstract}

Keywords: youth empowerment, child welfare, youth in care

Jennifer Dupuis is a Youth Empowerment Liaison at Batshaw Youth and Family Centres, 6 Weredale Park, Westmount, Quebec, H3Z 1Y6. E-mail: jennifer_dupuis@ssss.gouv.qc.ca

Varda Mann-Feder, D.Ed. (the corresponding author) is a Professor in the Department of Applied Human Sciences at Concordia University, 7141 Sherbrooke West, Room VE 227-3, Montreal, Quebec, H4B 1R6. E-mail: varda.mann-feder@concordia.ca 
Every year thousands of children and youth in North America are involved with child welfare systems. These systems can be defined as encompassing both social work practice and all the systems put into place to ensure the upholding of the safety, security, and development of at-risk children. In addition to theoretical perspectives based on the review of relevant literature, this article draws on the practical experience of co-authors Jennifer Dupuis and Varda MannFeder. Jennifer Dupuis, an alumnus from care, draws on her experience as a youth growing up under the jurisdiction of youth protection and her current experience as Youth Empowerment Liaison at Batshaw Youth and Family Centres, the youth protection organization that serves Quebec's anglophone population. Varda Mann-Feder is a professor at Concordia University, but worked for 27 years as a consulting psychologist in the anglophone child welfare system in Montréal.

Due to advances in the field of child development that began in the early 20th century, the universal rights of children and adolescents for protection have been adopted throughout the world (Mann-Feder, 2007). This has resulted in legislation in most countries that requires the protection of children and prescribes measures that must be taken when an individual child's development is compromised. As technical systems for youth protection have become more sophisticated, given electronic databases which enhance the capacity to track case files, there has been an increase in the number of interventions with families in Canada and the United States. A significant proportion of the young people involved have ultimately been placed outside their families because assessments have found their development to be seriously compromised. Being in care in the child welfare system can refer to a range of options along a continuum ranging from the most normative and individualized at one end (adoption) to foster care and group care at the other end. Provided under these options are either: (a) a substitute family, with a member of the child's extended family or an adult known to the child; (b) group home care, which acts as a therapeutic group setting; or (c) residential placement, which is similar to group home care but much more structured. Children can have long-term placement in any of these options or can move along the continuum through the course of a placement career.

Many factors influence outcomes in child welfare, and with an increased emphasis on evidence-based practice, outcome studies have proliferated. Results overall have provided a mixed picture of the long-term adjustment of youth who have been subject to intervention in the child welfare system. It is generally accepted that youth who have received services can grow into healthy and successful adults. However this outcome reflects a complex interaction between characteristics of the young people themselves, and a range of ingredients that characterize their experiences in the system. A factor that has been identified as helpful for youth in the care of child welfare particularly is the degree to which they had a say in their own care experiences, and were given some power and control in the relationship with decision-makers in their trajectory through the child welfare system.

\section{Defining Youth Empowerment}

Empowerment can be defined as "a process of increasing personal, interpersonal, or political power so that individuals, families, and communities can take action to improve their life situations” (Pearrow, 2008, p. 202). Youth empowerment in child welfare involves power 
International Journal of Child, Youth and Family Studies (2013) 3: 371-380

sharing between adults and youth, allowing the youth to become active agents of change (as opposed to simply service recipients) in an effort to encourage youth to improve their own lives. The goals of youth empowerment can be subsumed under a broad definition of "emancipatory practice”, an approach which "illuminates power dynamics in adult-youth relationships....with the goal of improving organizations to build stronger communities” (Linds, Blanchet-Cohen, Mann-Feder, \& Yuen, 2010, p. 5).

\section{Goals of Youth Empowerment}

There are numerous benefits to empowering youth in care, and using an empowerment model serves many functions. Gibson (1993) identifies the main goal of youth empowerment as helping those who come from disadvantaged groups to believe and understand they have control over the outcomes in their lives, and aiding them to realistically identify the oppressive barriers they face. Essentially, the capacity of individuals to improve their situation is determined by their ability to "control their environment, connect with needed resources, negotiate problematic situations, and change existing social situations that limit human functioning” (Gibson, 1993, p. 389). Empowering youth in care can result in significant long-term benefits, including enhanced self-awareness and social achievement (Pearrow, 2008); improved mental health and academic performance (Pearrow, 2008); reduced rates of delinquency, substance abuse, and school dropout (Roth, Brooks-Gunn, Murray, \& Foster, 1998; Pearrow, 2008); and reduced violence (Pearrow, 2008).

\section{History of Youth Empowerment in Child Welfare}

Historically, children were seen as objects rather than as people. By the 19th century, there was still no legislation to protect children from abuse or neglect as they were largely viewed as the property of their parents, who could do what they pleased with their children (Denov, 2005). The general consensus at the time was that children should be seen and not heard, and there was no concept of a young person having a voice.

Slowly things began to shift and from approximately 1867 until the mid-20th century a new view was adopted in relation to children. By the mid-20th century, children and youth in North America were considered a separate class of individuals who were vulnerable and had a need for care, and the movement to care for children in the United States trickled down to Canada. The state accepted responsibility for the welfare of vulnerable youth by establishing organizations to meet their basic needs. By the end of World War II there was another shift in the way children were viewed; they began to be seen as people who had their own unique rights. These rights were officially recognized in 1959 when the United Nations adopted the Declaration of the Rights of the Child (Denov, 2005).

Support for the voice of the children as accepted and valued continued to evolve, and in the 1970s the National Youth Development Bureau was established by the U.S. Department of Health, Education and Welfare. By the 1980s, youth advisory boards, or groups of youth appointed by officials to offer their advice or opinions on identified areas, had begun to appear. 
International Journal of Child, Youth and Family Studies (2013) 3: 371-380

The establishment of youth advisory boards represented the earliest youth empowerment initiatives. Throughout the 1980s and 1990s, this was the only visible form of youth engagement in child welfare (Crowe, 2007). These youth advisory boards sprung up at various levels in the child welfare system, but at the same time they presented significant logistical problems. These boards were poorly run and were often understaffed and/or staffed by individuals with inadequate training. Practical aspects such as transportation for the youth and the provision of meals were not usually taken into account. There was little consideration for the school or work schedules of the youth sitting on the boards (Denov, 2005). Additionally, there was a lack of funds available for projects that youth wanted and these collaborations were experienced as tokenism rather than as active participation in partnerships. Collaboration and advice was sought from youth, yet little was done to implement any of their suggestions. Another significant issue was that the youth that were chosen to participate on these boards were only those who were perceived as doing well in their placements, and youth in care who were struggling were not represented (Denov, 2005).

By the early 1990s, projects that promoted youth empowerment were funded throughout the United States by the DeWitt-Wallace Foundation through organizations that focused on character building such as the YMCA, Boy and Girl Scouts, and the Boys and Girls Clubs of America. In 1992, the Child Welfare League of America joined in this effort and formally introduced the concept of youth empowerment to the child welfare community (Denov, 2005). Since then, this movement has continued to grow within child welfare agencies across North America. There has been a growing emphasis on developing relevant approaches and programs. However, there are still many challenges that child welfare agencies face in incorporating an empowerment model.

\section{Challenges to Youth Empowerment in a Child Welfare Context}

The literature of child welfare has increasingly endorsed a youth empowerment stance (Kaplan, Skolnik, \& Turnbull, 2009). This is reflected by the recent movement towards positive youth development models such as “The Circle of Courage” (Brendtro, Brokenleg, \& Van Bocken, 2002), an approach that stresses First Nations philosophies and non-hierarchical relationships with appropriate role models (Reclaiming Youth International, 2013). In practice, however, there are still considerable obstacles to such approaches in child welfare. There are inherent contradictions between the goals of youth protection and the goals of youth empowerment. Assuming responsibility for the security and safety of children in need of protection implies a paternalistic stance (Turnell \& Edwards, 1997), in which there is a focus on doing for vulnerable young people (Dumbrill, 2005). Service must be provided to individuals who are often involuntary recipients, and the legal obligation to intervene results in the exercising of authority over individuals and depriving them of their right to choose. Some theorists have stated that, "the nature of child welfare practice is in itself oppressive" (Child Welfare Anti-Oppression Roundtable, 2009, p. 8).

The necessity of providing involuntary protection positions youth (and their parents) in the child welfare system as passive recipients of services who are controlled for their own good. The shift in child welfare from controller to partner is considerable, and cannot be made without a significant commitment on the part of agencies and individuals (Adams \& Chandler, 2004). 
International Journal of Child, Youth and Family Studies (2013) 3: 371-380

This commitment would entail sustained efforts to transform the culture of care to a culture of collaboration, where policies and procedures stress partnerships with clients.

Compounding this emphasis on the power of the child welfare system over the young people in its care, the approach to intervention has historically been deficit-based. What this means in practice is that the point of entry into the child welfare system is the failure of parents to provide an appropriate environment for their children. The children, as a result, become clients. Workers are designated as experts whose role it is to assess the impact of neglect and abuse, and prescribe care plans that will compensate for deficits in parenting. Power and knowledge rests with the system, not with the clients themselves (Turnell \& Edwards, 1997), and the youth who are targets of these interventions have virtually no say in what happens to them. Ironically, they are deprived of a voice because they are perceived as vulnerable, but their inability to exercise any degree of control over their own lives renders them more vulnerable (Dumbrill, 2005).

Child welfare agencies, by their very nature, tend to be funded by government and structured as large bureaucracies with strong links to the judicial system. In practice, this can result in organizations that are large, complex, and hierarchical. Not only is this confusing for young people, it is disempowering. Decision-making processes are most often top-down and do not even allow for the expression of individual client views and preferences in relation to the future. Services to youth and families are provided in separate departments that function as silos (Mann-Feder \& Guerard, 2008). These structures are difficult to navigate and discourage meaningful participation. The extent to which formal rules are generated by these large bureaucracies to regulate practice also results in a dynamic in which front-line workers are themselves controlled, and in turn manage their interactions with youth by placing emphasis on regulation and discipline (Fleming \& Spicer, 2003).

While interest in developing a youth empowerment approach has grown considerably in the last two decades, in practice agencies tend to underestimate the depth of the change that is required to sustain true youth empowerment. Because the culture of child welfare has developed in the context of the value system described above - that is, deficit-based, expert driven, and bureaucratic - deep reflection, preparation, and willingness to engage in a cultural shift is critical. It is paramount that all the adults involved embrace a willingness to give up their own power in order to truly empower youth (Dumbrill, 2005).

\section{Recommendations for Practice}

Recommendations for incorporating youth empowerment into a child welfare model of practice must be made at individual, organizational, and policy development levels. In implementing youth empowerment, it is crucial to look for opportunities to engage child welfare clients in current procedures in our agencies, but we must also co-create new possibilities for participation. Simply inviting youth participation at meetings is not enough; the values of youth empowerment must be incorporated into the "mission, values and practices" of our organizations (Romanelli et al., 2009, p. 203). In order to adopt a youth empowerment approach in child welfare, preconditions that can result in the establishment of a culture of empowerment must exist. 
Multiple tasks are involved in order to meet these conditions. The Child Welfare League of America recommends that youth be given meaningful involvement in decision-making around their own care, but that they also have opportunities to participate in leadership roles in relation to policy and program development, both as current care recipients and as alumni of care (Kaplan et al., 2009). Ensuring that a commitment to youth empowerment exists at every level in the organization is one of the greatest challenges when attempting to implement this model, but it is critical to the successful adoption of an emancipatory approach. Youth participation can quickly deteriorate into tokenism, which is more destructive to the aims of child welfare than not attempting these initiatives at all, because the misuse of youth involvement undermines the development of the capacity for agency and self-determination.

Individual level. At the individual level, workers require support, training, and the necessary tools to implement a youth empowerment model. Firstly, workers need time and support to examine the values underlying their current practices and to help them determine what shifts can be made to move from a coercive approach to establishing partnerships that promote meaningful involvement with the youth they serve.

As with any new approach, some workers may be reluctant to change their practices without being entirely sure about what it entails. The first step is education. It is critical to offer staff members training in an effort to challenge some of the negative myths associated with youth empowerment practice (for example, that it provides clients with opportunities to misuse their power and in some way overpower staff). The training should highlight the ways in which this approach is consistent with the worker's current practice. While most staff have been trained in counselling approaches that advocate that the clients are experts on their own lives, this message often gets lost in practice. This is especially true when practitioners take on a youth protection mandate and consequently feel they must adopt an attitude of I know what's best for you. Though this is done with the client's best interest at heart, it fails to consider the impact on a young person and his or her relationships with the worker and the organization. Young people in care often feel powerless over their own lives and feel as though their thoughts, desires, and opinions are neither valued nor welcomed. Reminding workers of this, and highlighting how the adoption of empowerment practice does not mean discarding previous ways of working but rather making more room for youth input, can ease the anxieties of child welfare professionals.

It is equally important that training highlights the benefits of a collaborative approach, allowing practitioners to adopt a positive view of the model. A critical issue to explore is the fear that workers may have about the need to reconcile legal obligations to clients and the potential loss of control implied in youth-adult partnerships. Open exploration will encourage staff to be more receptive to the possibilities afforded when youth voice is maximized and their role with clients shifts to create space for young people to express themselves.

Ensuring that practitioners have the necessary tools to operationalize the model is also key and requires appropriate and specific training. These tools can range from theoretical understanding to concrete information and materials for implementation. Not only are written manuals required, but standard tools that are used with clients need to be revised to ensure that they are consistent with the approach and that youth are fully informed about their rights and 
entitlements (Romanelli et al., 2009). This includes the creation of youth-friendly intervention plans, and the modification of rule books for programs in which youth input is solicited. It is equally necessary for staff to be aware of potential challenges in empowerment practice and to be equipped to deal with them. Resources must be made available to practitioners to help them realize the projects or changes that are necessary to encourage youth voice. Caution must be taken to ensure that when youth bring forward suggestions, individual staff members are given the authority and the means to implement them.

Organizational level. At the organizational level, evaluation should happen regularly for all employees, and incorporate ongoing discussion of the impact of shifting to an empowerment approach. This offers front-line practitioners an opportunity to examine in-depth what is working well and what isn't, and also provides an opportunity for feedback and support for improvements. The focus of supervision should be on supporting staff to find new ways to work collaboratively with their clients, as their own empowerment is critical to their capacity to, in turn, empower young people. The adoption of universal supervision practices across the organization can facilitate the adoption of a culture of empowerment.

In order to avoid gaps between the practices of upper management and front-line workers, the organization must take steps to avoid a broken telephone phenomenon, in which messages get lost. Accountability is important, as is a focus on measurable outcomes (Romanelli et al., 2009). A clear message needs to be conveyed by upper management about the adoption of this approach and expectations of employees. Principles of empowerment should be embedded in all agency documentation and all levels of staff need to be made aware of their responsibility for contributing to the promotion of youth voice (Romanelli et al., 2009). If upper management supports this new approach and consistently conveys this message to those at the level below them, it will permeate down to front-line workers. Given the size and hierarchical nature of child welfare agencies, opinions or interpretations are often added each time that a message is passed on, until the direction becomes skewed and unclear. Regular supervision to ensure that the new approach is being implemented is necessary, as is an action plan to address individuals or programs that are not successfully incorporating values of empowerment. The organization must take steps to ensure that all practitioners are being given the opportunity to explore their successes and challenges with implementation. Furthermore, management must ensure that any resistance is addressed and be prepared to follow up on obstacles to implementation of the model when necessary.

Policy development level. At the policy development level, a shift from an approach in which the emphasis is on doing for clients rather than working in partnership is needed to truly embrace the incorporation of empowerment practice into child welfare. Success will only be possible when youth are viewed as active agents of change in their own lives, as opposed to passive recipients of service. This necessitates that youth are represented at every level in the organization and have opportunities to use their own voices. Areas where opportunities already exist should not be the sole focus of implementation. In order to truly have a holistic approach, forms of collaboration with youth must be expanded. A common example of this is that in most child welfare agencies, team meetings take place weekly in all residential units where youth are placed. Often individual youth are given the opportunity to submit a list in writing to request items that they need. This procedure could be expanded so that the youth's voice is actually 
International Journal of Child, Youth and Family Studies (2013) 3: 371-380

heard. A portion of the meeting could be planned for youth to enter into dialogue with staff, allowing them to: (a) make suggestions about improving living conditions, (b) ask questions that they may not normally have the opportunity to ask, and then (c) be given the opportunity to receive feedback.

The collaborative creation of a new process could even extend to inviting one youth per week to participate in parts of the meeting where confidentiality is not an issue, to act as a liaison between staff and youth. This can be taken even further by arranging regular meetings for all youth with staff and management, with the goal of increasing opportunities for communication and collaboration. In order to relate to youth as partners rather than service recipients, youth must be given a say in the functioning of the units where they live. This, in turn, will lead to a higher likelihood that they will follow the rules they helped to establish, and will further contribute to their experience of being respected and empowered.

As a final thought, it is essential to not only find pre-existing opportunities but to create new ways to empower youth within the child welfare context. Having a voice in relation to placement experiences is a critical component of successful outcomes for individual youth, but it can also result in better programs and policies for all. It is critical that youth empowerment be incorporated into all elements of child welfare practice, not just as an isolated activity or through assembling a single group or advisory board, but as a holistic, ongoing approach incorporated into every level of our systems. It is important to remember that the adoption of a culture of empowerment is both an outcome and a process, which can take years to successfully navigate. Immediate transformation cannot be expected, but rather success can be measured by close attention to the gradual shifts that are taking place in our practice. 
International Journal of Child, Youth and Family Studies (2013) 3: 371-380

\section{References}

Adams, P., \& Chandler, S. M. (2004). Responsive regulation in child welfare: Systemic challenges to mainstreaming the family group conference. Journal of Society and Social Welfare, 93, 270-299.

Brendtro, L., Brokenleg, M., \& Van Bocken, S. (2002). Reclaiming youth at risk: Our hope for the future. Bloomington, IN: Solution Tree.

Child Welfare Anti-Oppression Roundtable. (2009). Anti-oppression in child welfare: Laying the foundation for change. Retrieved January 10, 2013 from http://www.oacas.org/pubs/external/antioppresssive.pdf

Crowe, K. (2007). Using youth expertise at all levels: The essential resource for effective child welfare practice. New Directions for Youth Development, 113, 139-150.

Denov, M. (2005). Children's rights, juvenile justice, and the UN Convention on the Rights of the Child: Implications for Canada. In K. Campbell (Ed.), Understanding youth justice in Canada (pp. 65-84). Toronto: Pearson Education Canada.

Dumbrill, G. C. (2005). Child welfare in Ontario: Developing a collaborative intervention model. Toronto: Ontario Association of Children's Aid Societies.

Fleming, P., \& Spicer, A. (2003). Working at a cynical distance: Implications for power, subjectivity and distance. Organization, 10(1), 157-179.

Gibson, C. M. (1993). Empowerment theory and practice with adolescents of color in the child welfare system. Families in Society, 74(7), 387-396.

Kaplan, S. J., Skolnik, L., \&Turnbull, A. (2009). Enhancing the empowerment of youth in foster care: Supportive services. Child Welfare, 88(1), 133-161.

Linds, W., Blanchet-Cohen, N., Mann-Feder, V., \& Yuen, F. (2010). Transforming practices: Emancipatory approaches to youth engagement. Unpublished grant proposal submitted to the Social Sciences and Humanities Research Council of Canada.

Mann-Feder, V. (2007). Issue editor's notes. New Directions for Youth Development, 113, 1-8.

Mann-Feder, V., \& Guerard, G. (2008). Organizational factors in the transition to independent living. Research report produced for a project funded by the General Research Fund of Concordia University.

Pearrow, M. M. (2008). A critical examination of an urban-based youth empowerment strategy: The teen empowerment program. Journal of Community Practice, 16(4), 509-525. 
International Journal of Child, Youth and Family Studies (2013) 3: 371-380

Reclaiming Youth International. (2013). Retrieved April 12, 2013 from http://www.reclaiming.com/content/about-circle-of-courage

Romanelli, L. H., Hoagwood, K. E., Kaplan, S. J., Kemp, S. P., Hartman, S. L., Trupin, C., et al. (2009). Best practices for mental health in child welfare: Parent support and youth empowerment guidelines. Child Welfare, 88(1), 189-212.

Roth, J. L., Brooks-Gunn, J., Murray, L., \& Foster, W. (1998). Promoting healthy adolescents: Synthesis of youth development program evaluations. Journal of Research on Adolescence, 8(4), 423-459.

Turnell, A., \& Edwards, S. (1997). Aspiring to partnership: The signs of safe approach to child protection. Child Abuse Review, 6, 179-190. 